\title{
THE PROBLEM SOLVING MANAGEMENT PROCESS AND THE BEST PRACTICE OF THE NATIONAL UNIVERSITY OF PUBLIC SERVICE Gábor KOVÁCS
}

\author{
National University of Public Service, Budapest, Hungary, \\ Kovacs.Gabor@uni-nke.hu
}

\begin{abstract}
It is the responsibility of the military and law enforcement leaders to solve different problems during their professional service. At the National University of Public Service the students study the main steps of the process of problem solving management. The essay leads the readers through the process of management step by step showing the best practice of the Hungarian military and law enforcement organizations. The essay pays special attention to the decision which is the main and most important step of the management process.

All of the graduating students of the National University of Public Service carry out an annual management practice - The Common Public Service Practice. The implementation of this practice following a theoretical phase is to support the practical knowledge applying the best leadership practice during solving the different situations in the real time.

The reader will gain a full insight into the problem solving management process and this experience can be successfully adapted to his own work.
\end{abstract}

Keywords: National University of Public Service, problem solving management, process of management steps, best practice of the Hungarian military and law enforcement organizations, management process, Common Public Service Practice

\section{Introduction}

Hungary placed in an area, where most of the people live in peace. I have to say, that this is only our first impression. We can determine from our professional view, that this 'peaceful life' is with full of danger and problems (crimes, natural dangers, illegal migration, dangerous industrial plants). The globalized impacts, the social and natural dangers are all threaten our lives. Full security - the lack of danger - is unthinkable. The tasks of the law enforcement organisations and other state organisations is to manage these dangerous situations and to decline detrimental effects. To manage these situations, the law enforcement and the military organisations have to work together, they involve other organisations in order to avert or to decline the threatening dangers and to diminish the detrimental impacts. In order to work in an effective way every leader [1] have to use the knowledge applying the best leadership during common work. One of the good example is the annual common practice which carry out at the NUPS university.

\section{About the leadership in General}

Without effective leading (commanding) process, there isn't a well-functioning and successful organisation. Leading an organisation is an extremely complex task, the leaders have to prepare for this. If the leader accomplish a challenge, he will be more confident and creative.

What is the secret of efficient leading? 
The exact and particular planning might be the key element of leading. In the law enforcement and military organisation, both the leader and the subordinate have to keep the law. These are regulating their working cooperation, which means that the subordinate have to execute the orders of the leader. It seems very simple, but in real life, this is not so easy.
What kind of practical advises can we give to the leaders? Let's see some classical examples. In order to achieve the leading goals, we recommend W. Edward Dewing's [2] principle.

\begin{tabular}{|c|c|c|}
\hline Nr. & $\begin{array}{l}\text { Practical advice } \\
\end{array}$ & Principle \\
\hline 1 & Create constancy of purpose for continual improvement. & Static \\
\hline 2 & $\begin{array}{l}\text { Adapt a new philosophy, always consider the proposals, if } \\
\text { you try them, and it works, use them. }\end{array}$ & Innovation \\
\hline 3 & Always be exemplary, always make qualitative work. & Be exemplary \\
\hline 4 & $\begin{array}{l}\text { Always think in long terms, do not give up your strategy } \\
\text { because of the daily interests. }\end{array}$ & $\begin{array}{l}\text { Long-term } \\
\text { thinking }\end{array}$ \\
\hline 5 & $\begin{array}{l}\text { Always train yourself, but do not forget to train your co- } \\
\text { workers and subordinates. }\end{array}$ & Self training \\
\hline 6 & $\begin{array}{l}\text { You have to supervise your leading methods, talk over them } \\
\text { with other leaders. }\end{array}$ & Self analysis \\
\hline 7 & $\begin{array}{l}\text { Lead your organisation calculable and measured. Motivate } \\
\text { your co-workers in positive way. Make an honest atmosphere. }\end{array}$ & Openness \\
\hline 8 & $\begin{array}{l}\text { Break down barriers between the units of the organisation. All } \\
\text { people have to work for the common success of the } \\
\text { organisation. }\end{array}$ & Synergy \\
\hline 9 & $\begin{array}{l}\text { Use a slogan which characterises your organisaton's activity. } \\
\text { Put it on the wall, where everyone can see it. }\end{array}$ & $\begin{array}{l}\text { Motivate your } \\
\text { co-workers }\end{array}$ \\
\hline 10 & $\begin{array}{l}\text { Support your colleagues, inferiors to be proud of their } \\
\text { military and law enforcement organisation. }\end{array}$ & $\begin{array}{l}\text { Success } \\
\text { orientation }\end{array}$ \\
\hline 11 & $\begin{array}{l}\text { If you have any opportunity, elaborate and create different } \\
\text { norms which your colleagues also accept and execute. In this } \\
\text { way, you can measure their achievement objectively. }\end{array}$ & Objectivity \\
\hline 12 & $\begin{array}{l}\text { Organise trainings in order to improve the skills of your } \\
\text { colleagues and inferiors. }\end{array}$ & $\begin{array}{l}\text { Development } \\
\text { of the co- } \\
\text { workers }\end{array}$ \\
\hline 13 & $\begin{array}{l}\text { Sometimes go on a trip together, lunch together or celebrate } \\
\text { the special events (e.g.:promotion, different annual } \\
\text { ceremony). Organise sport events and do sport together. All } \\
\text { of the members should wear group T-shirt especially made } \\
\text { for the event. It helps to strengthen the team spirit. }\end{array}$ & Collectivity \\
\hline 14 & $\begin{array}{l}\text { Begin to support the potential descendants of your staff, } \\
\text { remember - you cannot be here forever, probably, if you do it } \\
\text { right, you will manage a higher level of organization and the } \\
\text { leaders in the lower level will be "your people". }\end{array}$ & Team making \\
\hline 15 & $\begin{array}{l}\text { Strengthen your work mates in order to be interested in } \\
\text { developing the organization. Make sure they understand that } \\
\text { the success of the work is common interest. }\end{array}$ & $\begin{array}{l}\text { Reconciliation } \\
\text { of Interests }\end{array}$ \\
\hline 16 & $\begin{array}{l}\text { Do not forget that your colleague's success is yours and vice } \\
\text { versa. You have to know what are the strengths and } \\
\text { weaknesses of your colleagues. Stand up for them, help them }\end{array}$ & Teamwork \\
\hline
\end{tabular}




\begin{tabular}{|c|l|c|}
\hline Nr. & \multicolumn{1}{|c|}{ Practical advice } & Principle \\
\hline & to find the right solution to their problems. & \\
\hline
\end{tabular}

The requirements of law enforcement and military leadership

These are the most important requirements what we have to enforce as a leader.

1. Continuity means that leading have to be uninterrupted in every circumstance. Our co-workers have to feel the care of the leader, that their success, achievement and their failures are follow with attention. The leader should explain the next tasks to the subordinates and make sure that the subordinate understand the main tasks of the work. The workplace must be a well organised substitution system.

2. Strength means the resolve to carry out the tasks. The leader must insist the execution of the planned task. Do not afraid of the difficulties, find out how to solve the problem more effective and to expend less energy.

3. Flexibility is the reaction and sensitivity to the occurred changes. The leader has to make a new decision, depending the changed situation. It seems this is the opposite of the principle of strength, but this is the requirement, the leader must change his decisions in case if the organization cannot achieve the appointed goals and aims.

4. Consistency provides predictability. During the leader's work process, he has to express one's work objectively even if it is positive or negative sided. The co-workers must feel that their positive work performance is followed by their leader. The application of this principle helps the work experience, the leadership practice, the routine, the former positions in different levels.

5. Prevision is the recognition of the circumstances which influences the activity. The leader have to have a breadth of view according to the information, he has to see the impacts of his decision. The leader can use the SWOT analysis (Strength, Weaknesses, Opportunities and Threats) to analyse the possible impacts.
6. Operativity means that the leader have an ability to recognise and solve the problem. He has to find the solution as quickly as he can. The subordinates expect from their leader to find the solution and solve the problems. The analysis and evaluation can help to solve this task.

7. Purposive means that during the leadership process the leader have to connect the tasks and the sources in order to solve the different problems. The main characteristic of the principle of purposive is the good planning system. Every well organised organization need long, middle and short term planning structure.

8. Undercover. Keeping this principle provides the suddenness and surprise. It means that everything have to goes well, even if the leader is not there. It is important when there is a threatening impact while running the organisation.

Key principles and characteristics of the management of law enforcement agencies and the military organizations

During the management process the leaders must keep the following principles.

- The principle of personal leadership methods. The responsibility of the leader is wide-ranging. $\mathrm{He}$ is responsible for the process, the activity, the staff of the whole organization. The professional law enforcement or military staff has a right to give an order for the professional and nonprofessional subordinates.

- The principle of the centralized management structure. The command structure of law enforcement and military organizations is organized according to hierarchy. This connection is strength and strict between the leaders and commanders. The main tasks of all commanders and leaders are the full implementation of the received orders, commands (actions, instructions).

- The subsidiarity principle means that if it is possible all decisions should make at the lowest level, where the greatest experiences, knowledge and competences 
can be found. The decision-making problems will be forwarded to the higher levels of management, if they do not have adequate powers to carry out the decision at that level. A well-designed organizational structure, where the management levels and professional profiles are divided can help us solving this. The managers and the modus operandi of the organizations can clearly define the decision-making competencies. It also assists in the precisely designed implementation of the reporting and disclosure requirements, the regulation of formal and informal contact.

- The principle of the initiative of the subordinates. During the implementation of the new situation, the subordinates should give every new information for the leaders. The different changes occurring different events. The self-motivated subordinate, the proactive attitude allows precise knowledge of the situation. The leader will be able to select the best solution during the evaluation process. Create favourable conditions for the application of the principle that the leadership is open for the employees. The good solution is that, the employees are well-prepared subordinates, they are initiative and wellinformed, so they can give successful proposals in order to solve the problems.

- The principle of constant readiness. In the different levels, the different leaders of the law enforcement and military organization should be ready at all times to address unforeseen and unexpected situations and tasks. There must be always a second backup version, which can provide an alternative solution in case of change the situation.

- Ensuring logistics management. It means - provide the materials, information, people, systems, energy at the right place and in the right time. In practice, it means that, without the help of the superior leading organization, the subordinates could not able to fulfill their tasks. In general, the logistics organization part is a specialized creation of the infrastructure. This area includes: accommodation, food, transport,
IT security, energy security, mapping, board, clothing care, provision of technical equipment, providing logistics services to ensure the professional staff. The logistical tasks can be summarized by nine criteria: the right information, the right materials, the right energy, the right people, access to adequate amounts of the right quality at the right time, right place and right cost.

- The principle of cooperation. The military and law enforcement organization can only be effective when the subordinated organizations and leaders cooperate and coordinate the activities. Each participating subsystem knows their own activities and their tasks properly. The basic and essential philosophy of success is the well-organized cooperation. With the cooperation as a tool, we can save sources, using the successful implementation of the activities. The cooperation organized from the upper management levels to the lowest level. It is fruitful between the subordinate departments or individuals. The cooperation is effective if it is based on the partnership relations between the same levels and on mutual benefit and reciprocity.

- The principle of synergy. This is a cooperation, co effect when more items or co-factor gives the higher performance. The higher income is created if the elements or factors simply add. It is the main goal of the principle to concentrate the quantitative and qualitative focus effect. It helps to facilitate the application of this principle, if adequate reserves and authorized resources are available to the management.

\section{Leading process, the functions used in the law enforcement and military organizations}

All of the leading functions help the leader to manage the successful activity. In the special management bibliography, the management process has very broad background, which will be presented in a version.

Occasionally, the process can be very flexible, because certain management functions can be repeated or returned to the fore. All management function prepares the 
successful activities that serve to get the most of the work done by the organization.

The leading functions used in the law enforcement and military organizations are the following:

1. collecting, analysing and using the information

2. planning (making the different variations of the decision, preparing the decision)

3. decision making (the most important leading function)

4. organizing, coordination (to execute the decision)

5. leading (leading the tasks)

6. controlling and evaluation

\subsection{Collecting, analysing and using the information}

The successful working assumption of the leaders are considered to be constantly and they have to manage and operate the necessary information led by the activity.

In the well-organized information system the leaders are available, they receive internal and external information about the organization. The processing of this information is essential, as they have an impact on the organization's activities. The basic condition of the successful leader work is that, the leader always have to have the necessary information in order to manage the organization.

The information sources can be external and internal information. External information -receive the information from the environment outside of the organisation (E.g.: information from the inhabitants). Internal information - related to the information from the organization (E.g.: forces and instruments, people and organisations who cooperate with us)

Measurement of the information can be quantitative information: numbers, percentage (E.g.: headcount) and qualitative information: cannot measure in numbers (E.g.: the motivation of the people)

The type of the information can be primary information - when they receive the information directly from the body and secondary information - when it comes to transmissions of information through the user.

The circulating of the information can be vertical - where the information flow from top to bottom or vice versa (data in higherlevel management body to convey intelligence organization) and horizontal where the information flow between the bodies on the same level.

Based on the time factor it can be: for the past, present or future, related to time to the past, to the present, to the future.

All of the information may: complete or incomplete, inaccurate or accurate, reliable or unreliable, true or false, controlled or uncontrolled, current or not current.

\subsection{The reception of the task - the task clarification}

The task taking and task clarification are in the first place in the management (command) work's order, a though process, when the leader (commander) understands, captures and organizes the given task and develop the appropriate actions to be taken and make his large-scale approach.

Depending on the nature of the task, immediately regulations can give out or instructions for implementation of those measures can be introduced, which will help to prepare for the implementation of the tasks.

This theme is carried out when we recognize a task or we get some instruction on what the leader expect from us or from our organization. It is very important for you to identify the task and set up a precise idea. If any details are not entirely clear, it should specify at this stage.

The time management is the most appropriate allocation of time available between the leading organization and the subordinates organizations, in order to carry out the task successfully.

This process can be determined by:

- the necessary time till we perform the tasks;

- the dark and light time of the day;

- part-time units, which are necessary for the implementation of the main tasks; 
The available time should be allocated between to the leading and implementing organization is $2 / 3$.

\subsection{Planning (making the different variations of the decision, preparing the decision) \\ Planning is a leadership function when the commander sorts the tasks which have to be solved. He takes into consideration the available forces and implements and decides which task is the most important.}

The design of the overall process may include:

1. Analysis, the difference between the actual and the desired situation.

2. The support and barriers census.

3. Making different action plans in order to achieve our goal.

On the higher level of leading, the planning process is more general. On the lowest level of management, the detailed plans are necessary. The planning is a complex process, which consists other management functions also (eg.: analysis of the evaluation, the decision of the control). Ideas developed during the planning phase, which is usually the order of tasks. During the planning, the leader realize, who is the responsible person, how can achieve the targets, the method of implementation, the involved organizations of the implementation and the individuals, the staff - who execute the tasks, the deadlines for implementation.

The planning process can be used in the following ways of working. The law enforcement agencies and the military organizations can use these planning methods: sequential method, parallel method, and combined working method.

1. Using the sequential method, the planning in different levels of management are carried out sequentially. When the planning on the higher management level is completed, the next management level, the subordinate organizations and leaders begin the work. Each management levels carry out their task "staggered". This method is usually used when there is sufficient time to plan and carry out the task.
2. Using the parallel planning method when the higher management level finish the work and after that they give the order for the lower-level organization at the same time. The upper level is carried out the planning process. This way of working methods used when there is the short time period for the preparatory work. The leading organs carried a certain time lag, planning out their tasks in parallel.

3. When using the combined planning method some planning level is working together to apply the sequential and parallel planning methods. It is a good solution - for example - two organization are working at the parallel or sequential working method, and the lowest level is working with the different methods. This way of working methods will reduce the time for planning. In case of emergency this is useful, because the organizations save time at the planning process.

\subsection{Decision (the most important management function)}

The decision is a management function, when the leader form some variation and choose one version in order to attain the successful activity.

The main elements of the decision making process:

1. Recognize the situation, in which we have to make a decision (Do we have a pressure to decide?)

2. Draft the problem (What is the problem? What are the goals and opportunities?)

3. Collect and select the different kind of action plans (When, what and in what order we have to do to reach our future goal)

4. The decision (Choose the best version)

Related to the decision these are the following possibilities:

- Adaptive decision when the leader have to adapt the order from the higher level organization. In this case, the leader has only limited decision alternatives;

- Various decisions - when the higher level organization work out the alternatives and we adapt the best alternative. In this case the leader have the opportunity to make the decision. 
- Free-ranging impact decisions when the law enforcement and military leader realize various decision alternatives, working on the optimal choice. In this case the full responsibility of the decision rests on the shoulders of the leader.

Based on the characteristics of the decisionmaking situations, the decisions could be the following:

- The recognizable decision we can realize and pre-model the effect of the decision. Such decisions are usually belongs to the basic activities of the organization, marking the well-defined rules and forms.

- Risky decisions are the type of the decision where unknown factors may have deep impact on the decision. In most cases, these decisions are based on hypotheses that are realized or not. The assumed risk can significantly reduce by the effectiveness of the leading professional experience and skills of the organization and the leaders.

- Uncertainty decision taken in situations where the necessary information is not available to make the decision, but the leader is forced to decide. In this case, the problem occurs suddenly, the leader's decision implies the possibility of failure and success, the outcome is largely dependent on the expertise of the leader's professional and personal experience.

The forms of the decision are the following according to the commander's leading style:

- Personal decision when the leader trusts his own skills, knowledge and experience and make a decision according to the basis of the available data.

- Systematic decision when involving lower-level leaders and professionals usually apply with the classical decisionmaking methods - the decision-making process is collective.

- Scientific decision during the decision process the leader selecting the appropriate variations according to scientific methods (eg .: proposals of scientific bodies, mathematical statistics, game theory methods, models, algorithms analysis).
- Corporate decision that the organization's operational rules define and characterize the decision. This decision is compulsory for the minority.

Choosing from the different forms these are the important factors: the personality, the leading method of the leader, the motivation and social sensitivity, whether there is enough time to construct the decision or not.

General requirements for the decisions:

- the decision have to comply with the functions and "interests" of the organization,

- can be fulfilled in the subordinate organization;

- the tangible, intangible and human factors should be available to the execution;

- have sufficient time for implementation;

- be grounded by technically and scientifically;

- the majority of the members of the organization have to support the decision and its implementation.

Typical problems and failures of the decisions:

- the leader does not recognize the decision situation;

- the leader does not admit the mistakes of earlier decisions;

- the conditions are not enough for the implementation;

- take hasty decisions, not properly consider the realistic possibilities; delay the decision;

- there is not enough time to carry out the decision;

- the decision is not supported by the majority of the members of the organization.

\subsection{Organizing, coordination (to execute the decision)}

The leader of the organization coordinate and harmonize the different work methods in order to achieve a specific goal of the organization. This work essentially involves the organization processes, the creation of the new organization and to organize of the different work elements. 
The coordination is a management function when the leader:

1. formulate and plan the follow-up activities (construction engineering);

2. deliver the information to the subordinates (release provisions);

3 . coordinate and organize the tasks with the subordinate leaders and colleagues;

4. ensure all material and immaterial component which are needed to achieve the goals of the organization.

In the management system it is essential to deliver the tasks to the leaders of all subordinate organizations, who forwarded them to subordinates as well.

\subsection{Leading (leading the tasks)}

The leading is a management function, when the superior intervene into the leadership process in order to start and maintain the required level. When it is necessary the leader can change, stop or start again the implementation process.

The leading doesn't mean to restart the management process, it means to realise the less distractions and bypass.

\subsection{Cooperation}

The cooperation is a management activity in which the leader organize and coordinate the organizations activities according to - goal, task, location, time of execution, method.

The purpose of organizing the cooperation. All subordinate commanders interpret what the task, which the terrain can organize the activity.

Methods of implementation:

- the methods of the commander's instructions (when there is little time available);

- the methods of the subordinate's report;

- the main features of that activity playing by the subordinates. They play the main elements of the activity, the commander approves or modifies the collaboration.

The implementation of the principles: person to person; body of the body; level of management the management level; it is organized from top to bottom; always happens to the main task.

\subsection{Controlling, evaluation}

Controlling is a management function when the leader, make sure where are the inferiors in the executing tasks process, how did they execute that, is it possible to reach the goal. Based on this check the commander gets information about how the tasks being executed. If it is needed, he can make a new decision.

Parts of controlling:

1. Get to know the real situation

2. Contrast the real situation and the state we want to achieve

3. Explore the similarities and differences

4. The causes of differences

5. Abolish the causes

6. Modify the original goals

7. Making new goals

The leaders have to control their inferiors and the organisation's work. Without this, they wouldn't have appropriate quality and quantity of information, what would be disadvantageous for the leader as well as the executors.

The control should be:

- the controller have to be awarded during controlling

- be professional

- be complex

- explore the mistakes

- sometimes it should be a surprise visit

Requirements for control: be prepared to control the implementation of the audit; be objective; be professional, systematic and consistent; the time to find the errors; develop personal responsibility; strengthen the law and order; be helping nature; targeted nature; comprehensive (complex); to the substance; don't be fault-finding; where appropriate, be surprise (regular, irregular with repeated).

\subsection{Evaluation of the activity}

During evaluation, the leader strengthen the inferior whether he made the task good or bad.

3. During 2013 year's practice "Vadvíz 2013 - White-Water 2013" - the main tasks were the following

The knowledge of leadership process is vital at the National University of Public Service Students life. During the semesters, 
all the students acquire the knowledge of the leadership methods. The excellent opportunity to use these skills at the practice. In the past two years the leadership of the university organised the Common Public Service Practice. The results of these practices are valuable, the activity was fruitful and meant a great success to the participating students. The topic of this practice was different in both years.

The topic of the 2013 year's practice was the task required from the public service organizations during the flood emergency situation in the homeland (to maintain the public order, to handle the illegal immigration, the relocation of citizens and the relocation of a prison).

The military students in the frame of the practice focused to another topic. It was the preparation of the peace keeping mission of the special units of the Hungarian Army and the preparation during the emergency situation caused by the flood.

Throughout the practice - simulating the real life - the Disaster Management Organizations began the process as if it had been a normal situation. They started the preparation process in order to avoid the flood at the area by the river Tisza. The organizations practised the management tasks according to the competences of different levels: They planned, organised and implemented and controlled joint activities, developed cooperation among the following units, the European and another national and international organizations, the authorities of neighbouring countries, the homeland law enforcement, the public service and military organizations, the nonstate and charitable organizations which took part at the clearing process of the emergency situation.

Some parts of the Hungarian Army provided some sub tasks in peace keeping mission. The staff prepared the relocation of different subunits to the crisis zone, the coordination and managing the peace keeping mission, the activity at the weapon free zone, the cooperation with the governmental and non-governmental organizations. The brigade according to the tasks and together with the international liaison officers carried out the peace keeping mission.

\section{The Implementation of the "Végvár 2014" "Last Fort 2014" Annual Common Public Service Practice}

The number of participants in this year increased, one university campus couldn't provide enough working place for the participants, so the leaders decided to use parallel working method during the implementation of the practice. The same practice was to be run at two different campuses so the umpires can handle coordination and monitor the students.

In order to make the practice successful the staff prepared a special mission for each profession and it was tailor made for the police (the following specializations: border guard, criminal investigation, public order), the military (artillery, tank unit, etc.) and the public administration students.

During the preparation phase, the teachers held a lecture to the students on how to solve different problems in the frame of the decision making process, how can they work together in order to solve different problems. The topic of the Common Public Service Practice in 2014 was different [3]. During the preparation period the staff prepared a detailed fictional basic situation. This situation provides all the possibilities in order to practise all the professions of the participating university students.

The virtual scene of the practice was the designated areas of Hungary. The real scene was the assembly room of the Law Enforcement Campus and the Military and Officer Training Campus. During the practice the students used the computer labs and the different special operation rooms.

Different organizations were created by the students on local, county and national level. In order to make the practice lifelike the different movements were carried out in real time at the training field. The continuous connection with the participants at the training field was provided by a video conference system and a satellite link. 
The graduating students acted as the organization leaders and the staff as well. Each participant carried out his task according to the competences of his respective organization. They used the forces and the cooperative organizations in order to solve the different situations.

\section{Conclusions}

The structure of the NUPS is special, to train the future military, law enforcement and public service experts in basic, master and $\mathrm{PhD}$ level in one organization. The special module - Common Public Service Module - special, the subject of Management Science provides common knowledge for all the university students during the bachelor education. This knowledge is necessary to the wellorganized work for the future experts. The
Common Public Service Practice is a vital part of the education. It helps the teachers to provide the practice oriented education. It helps the students, because they use their theoretical knowledge in order to solve the different practical problems. During the practice in the different positions, the students' work together - in team work, they realize the different problems and they find the common solutions.

The planning, organizing and leading of the practices were smooth, the experiences were useful and acceptable for the public service organizations.

According to the best Hungarian practice, the staff of the NUPS are ready to invite some foreign university teachers and students, in order to collect deep impression for the Common Public Practice.

\section{References}

[1] Leader - it means law enforcement and military commander - remarks of the author

[2] Principles and Practices of Organizational Performance Exellence Thomas J Cartin ISBN 0-87389-428-6 USA Milwaukee, Visconsin 53202; Out of the Crisis by W Edwards Deming. Cambrige, MA 02139. p:322-323

[3] State Reform Operative Program - 2.2.21, Knowledge-based Public Service Careers. The Civil Service Practice Concept and Development of the Task - Launcher, NUPS, Vice Rector for Education's Office, Budapest, Ludovika tér 2. 2013

\section{Bibliography}

Czuprák-Kovács (2013): Vezetés- és szervezéselmélet. NKE. Budapest,., ISBN 978-6155344-36-7

Principles and Practices of Organizational Performance Exellence Thomas J Cartin ISBN 0-87389-428-6 USA Milwaukee, Visconsin 53202; Out of the Crisis by W Edwards Deming. Cambrige, MA 02139. p:322-323

Common Core Curriculum Bachelor Education NUPS Faculty of Law Enforcement, Law Enforcement Management Theory Department 2013. Budapest, Ludovika tér 2

NUPS Common Core Curricula, Vice Rector for Education's Office, 2013. Budapest, Ludovika tér 2

Common Core Curriculum Master Education, NUPS Faculty of Law Enforcement, Law Enforcement Management Theory Department 2013. Budapest, Ludovika tér 2

Kovacs-Schweickhardt (2014). Organization and management system of law enforcement agencies Budapest: National University of Public Service, pp. 17-56. (ISBN:978-615-5305-79-5)

Kovacs (2014). The police staff's management practice. 225 p. Budapest: Hungarian Association of Police Science, pp. 141-151.(ISBN:9786155305511)

Kovacs-Horvath (2014). Management and organization theory of law enforcement agencies. $240 \mathrm{p}$ Budapest: National University of Public Service, pp. 57-92. (ISBN:9786155305412)

State Reform Operative Program - 2.2.21, Knowledge-based Public Service Careers. The Civil Service Practice Concept and Development of the Task - Launcher, NUPS, Vice Rector for Education's Office, Budapest, Ludovika tér 2. 2013 